\title{
Classification Accuracy of Body Mass Index for Excessive Body Fatness in Kuwaiti Adolescent Girls and Young Adult Women
}

This article was published in the following Dove Press journal: Diabetes, Metabolic Syndrome and Obesity: Targets and Therapy

\section{Hanouf Al Hammadi John J Reilly}

University of Strathclyde, Physical Activity for Health Group, Glasgow GI IXQ, Scotland
Correspondence: John J Reilly University of Strathclyde, Glasgow, Physical Activity for Health Group Glasgow GI IXQ, Scotland Tel +44I4I548 4235

Email john.j.reilly@strath.ac.uk
Purpose: Adolescent obesity, as defined by BMI, is amongst the highest in the world in Kuwait. This study aimed to determine the extent to which BMI might be underestimating obesity as defined by excessive fatness in Kuwaiti female adolescents and young adults.

Methods: A total of 400 apparently healthy Kuwaiti female university students (mean age 18.0 years, SD 0.6) were recruited. Excessive fatness was defined as body fat percentage $\geq 30$, measured using the Tanita model TBF-310 Bio-impedance system with the manufacturer's equation. Obesity was defined as recommended by the WHO in adult participants - those aged $\geq 19.1$ years - as $B M I \geq 30 \mathrm{~kg} / \mathrm{m}^{2}$. In the adolescent participants (age $<19.1$ years) obesity was defined as recommended by the WHO as a BMI-for-age $Z$ score of $\geq 2.00$. The accuracy of BMI-defined obesity to identify excessively fat individuals was determined by estimating the prevalence of obesity using high BMI and prevalence of excessive fatness, and by calculating sensitivity and specificity and predictive values.

Results: Median BMI was $27.8 \mathrm{~kg} / \mathrm{m}^{2}$ (range 15.1-51.2) and median body fat percentage was 32.0 (range 5.0-54.0). The prevalence of excessive fatness was $62 \%$ (247/400 individuals were excessively fat), while the prevalence of obesity according to BMI was 42\% (169/400 individuals were obese according to their BMI). The sensitivity of BMI to identify the excessively fat individuals was moderate (66\%) but specificity was high (96\%). The positive predictive value of BMI was $96 \%$ and the negative predictive value was $64 \%$.

Conclusion: BMI-based measures substantially underestimate the prevalence of excessive fatness in Kuwaiti adolescent females. Obesity is even more prevalent, and requires more urgent attention, than is apparent from BMI-based measures used in most research and national surveys. BMI may also be too crude for use as an exposure or outcome variable in many epidemiological studies of Arab adolescent girls and adult women.

Keywords: body fat, obesity, children, adolescents, body mass index

\section{Introduction}

The prevalence of child, adolescent, and adult obesity is very high in the Gulf Cooperation Council (GCC) states, among the highest in the world. ${ }^{1-4}$ Our recent systematic review found that obesity prevalence estimates for the GCC countries, like many other countries around the world, are currently based entirely on BMI. ${ }^{1}$ The World Health Organization (WHO) defines obesity as body fat accumulation to the extent which poses a health risk. However, since body fatness is difficult to measure, simpler proxies for body fatness are usually preferred for defining obesity in studies and national surveys. ${ }^{1,5,6}$ The WHO recommends that the best simple proxy for obesity prevalence is BMI, with 
obesity defined as BMI $\geq 30.0 \mathrm{~kg} / \mathrm{m}^{2}$ in adults or a BMI-for-age $Z$ score $\geq 2.00$ in adolescents (up to and including age 19.0 years as defined by the WHO).

Several systematic reviews ${ }^{7-9}$ of the classification accuracy of BMI in children, adolescents, and adults have concluded that using BMI is a conservative way of determining obesity prevalence, ie that sensitivity is low-moderate. This means that a relatively high proportion of individuals with an apparently healthy BMI or BMI-for-age are actually excessively fat. The problem of low sensitivity of BMI seems to be particularly serious in some populations, eg in a recent study of African children and adolescents the prevalence of obesity as defined by excess fatness was over three times higher than the prevalence of obesity as defined by BMI-for-age. ${ }^{6}$ Despite this concern about BMI, this source of bias when using BMI is not widely known. For example, our recent systematic review found 11 eligible published studies and surveys of obesity prevalence from the GCC states and none of these made any reference to biases in the estimation of obesity prevalence using BMI. ${ }^{1}$ The two most recent global estimates of obesity prevalence $^{10,11}$ also failed to refer to this source of bias when using BMI and BMI-for-age.

While an underestimate of obesity prevalence when using BMI to define obesity might therefore be expected, it is not widely appreciated, and the extent of the underestimate seems to vary substantially between human populations. ${ }^{12}$ At present, the extent of the bias when using BMI in Arab countries is unknown - none of the systematic reviews published to date found any studies of diagnostic accuracy of BMI from any Arab countries in children, adolescents, or adults. ${ }^{7-9}$ There is therefore a need for new evidence on the diagnostic accuracy of BMI in Arab populations so that the extent to which studies and surveys which have used it are biased can be assessed.

The problem of misclassification of obesity (excessive fatness) when using BMI goes beyond implications for estimating obesity prevalence. In many studies, BMI is being used as a proxy exposure variable, to test for associations between obesity and various adverse health and other outcomes, such as cognitive and educational attainment for example. ${ }^{13,14}$ In many other studies BMI is being used as a proxy outcome variable, to test for associations between various potential exposures (eg physical activity and sedentary behaviour) and obesity. ${ }^{15,16}$ The extent to which BMI misclassifies excessive fatness will determine the extent to which these studies can identify obesity as an important exposure or outcome. The ability to examine obesity as an outcome or exposure in our future studies in the GCC countries depends on the extent to which BMI misclassifies excessive fatness. If the degree of misclassification of excessive fatness by BMI is substantial in Arab populations, then body fatness should be measured directly in future studies, rather than using BMI as a proxy. ${ }^{17}$

The aim of the present study was therefore to assess the extent to which BMI might underestimate obesity (excessive fatness) in Kuwaiti adolescent girls and young adult females at university.

\section{Methods}

\section{Study Design, Participants, Consent, and Ethics Approval}

The present study was part of a wider prospective investigation of the impact of obesity on educational outcomes in a convenience sample of Kuwaiti female university students. Data collection took place at Kuwait University College of Social Science in February-May 2019 and was restricted to adolescents and young adults only (students in 1st and 2nd years), and to Kuwaiti nationals only so as to obtain a relatively homogeneous sample. Of the 3024 students in the College, 855 students were excluded as they were male or non-Kuwaiti, leaving 2169 students who were potentially eligible and so were invited to participate in this study. Students with issues which might affect their weight status and body composition were excluded (pregnancy, chronic illness, or injury which affected body weight, eg limb in a cast following a fracture). The study was approved by the ethics committee of the School of Psychological Sciences \& Health, Faculty of Humanities and Social Science, Strathclyde University, and all study participants gave informed written consent to participation. For study participants under the age of 18 years, a parent also provided informed written consent. This study was conducted in accordance with the Declaration of Helsinki. Additionally, Kuwait University provided approval to carry out this study at the College of Social Science.

\section{BMI-Defined Obesity - the Index Test of Obesity}

Height was measured using a Seca Stadiometer to $0.1 \mathrm{~cm}$ (Seca, London, England), and weight to $0.1 \mathrm{~kg}$ with study participants in light indoor clothing with the Tanita TBF310 leg-leg bio-impedance system (Arlington Heights, Illinois, USA). Both height and weight were measured by two trained and experienced observers, and both observers 
followed WHO guidance on anthropometric measurements using standard operating procedures. Since adolescents are still growing and BMI increases until growth has stopped, the BMI cut-offs recommended by the WHO to define obesity for adolescents and adults are different. ${ }^{5}$ For the adolescents (17.0-19.0 years of age) who took part, we defined obesity as a BMI $Z$ score of $\geq 2.0$ relative to WHO 2007 reference data ${ }^{5}$ using Anthroplus software. For those from 19.1 years of age, we used the adult cut-off point of $\mathrm{BMI} \geq 30 \mathrm{~kg} / \mathrm{m}^{2}$ to define obesity. Results of the body fatness estimates were not available to the researchers making the height and weight measures.

\section{Body Fatness-Defined Obesity, the Reference Standard}

Body fat percentage was measured by the Tanita TBF-310, using the manufacturer's equation for estimation of body fatness which is commercially sensitive and not available publicly. The device was used by two trained researchers on the same day as the height and weight measures, and they followed standard operating procedures based on the manufacturer's instructions. Study participants were asked to avoid strenuous exercise and eating and drinking for at least $2 \mathrm{~h}$ prior to the bio-impedance measure. Leg-leg bio-impedance estimates of body fatness are relatively insensitive to the timing of eating and drinking, and to the composition of the food and drink consumed, making the technique particularly practical for field and clinical applications. ${ }^{18,19}$ The purpose of using bio-impedance in the present study was based partly on practical grounds as it is quick, cheap, and painless, and poses little or no burden for researchers as well as the participants of the study, and so is especially suitable for field studies of this kind. ${ }^{20}$ Additionally, the Tanita device with the manufacturer's equation has been validated against alternative measures of body fatness in a number of studies in adolescents and young adults, and has been reported to provide acceptable estimates of fatness. ${ }^{21-24}$ Body fatness estimates from bio-impedance were not made known to those making anthropometric measures.

Previous studies of the diagnostic accuracy of BMI against body fatness measurement have used a variety of cut-offs for excessive fatness in adolescent females, but a cut-off of $\geq 30 \%$ has been used widely according to systematic reviews ${ }^{7-9}$. This cut-off originated from a major study which found that there was a sharp increase in cardiometabolic risk factors at $30 \%$ body fat in girls and women. ${ }^{25}$ Therefore, body fat $\geq 30 \%$ was used in the present study to define excessive fatness.

\section{Classification Accuracy Statistics and}

\section{Reporting}

The sensitivity, specificity, and positive and negative predictive values were calculated to measure the accuracy of BMI to define over-fatness. ${ }^{26}$ Sensitivity was defined as "the proportion of people with the disease with a positive result"; specificity was defined as "the proportion of people without the disease with a negative result"; positive predictive value was defined as "the proportion of people with a positive test result who actually have the disease"; negative predictive value was defined as "the proportion of people with a negative test result who do not have disease" ${ }^{26}$ Continuous variables were summarised as mean (SD) or median (range) as appropriate after checking for normality using plots and D'Agostino-Pearson tests.

Classification accuracy and diagnostic accuracy studies should follow STARD $^{27}$ (Standards for Reporting of Diagnostic Accuracy Studies) guidance, and so conduct and reporting of the present study followed this guidance.

\section{Results}

\section{Characteristics of Study Participants}

Recruitment into the study is summarised in a flow diagram (Figure 1). Of 2169 potentially eligible Kuwaiti female students, 525 agreed to participate, but 125 were ineligible (age 20 years or over, with chronic disease, injury, or pregnant): 400 eligible participants took part and among these 400 there were no missing data. Anthropometric and bio-impedance data were collected on the same day. Mean weight was $68.8 \mathrm{~kg}$ (SD 17.2) and mean height was $158.1 \mathrm{~cm}$ (SD 5.1), while median body fat percentage was $32.0 \%$ (range 5.0 to 54.0): see Table 1.

\section{Prevalence of BMI-Defined Obesity and Prevalence of Excessive Fatness}

The prevalence of excessive fatness was $62 \%(247 / 400$ individuals were excessively fat) while the prevalence of obesity according to BMI was 42\% (169/400 individuals were obese according to their BMI).

\section{Classification Accuracy Statistics}

The STARD checklist summarising adherence to conduct and reporting guidance for studies of this kind is summarised in Table 2. The sensitivity of the BMI-for-age definition of obesity was $66 \%$ (163/247 excessively fat individuals had a positive test for obesity according to their BMI; Table 3). The specificity of the WHO BMI-for-age was 96\% (147 out 
College of Social Science Students in 2019

Males, Females, Kuwaitis and non-Kuwaitis

(n) $=3024$

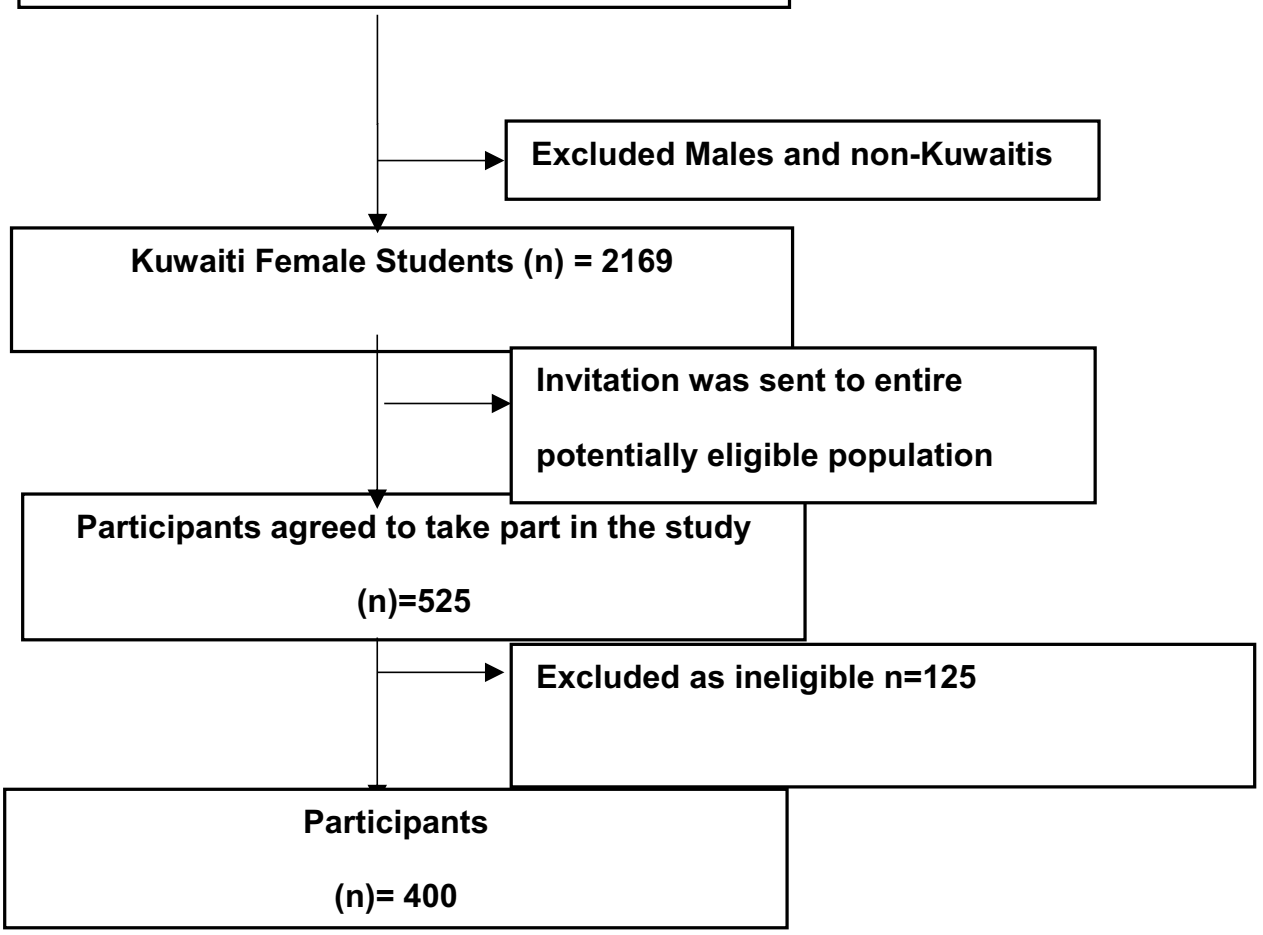

Figure I Flowchart of study participation

of 153 individuals not excessively fat had a negative test for obesity tests according to their BMI). The positive predictive value was $96 \%$ : 163 out of 169 individuals with positive tests for obesity were excessively fat. The negative predictive value was 64\%: 147 out of 231 individuals with negative tests for obesity were not excessively fat.

\section{Discussion}

The main finding of the present study is that BMI substantially underestimated the prevalence of excessive fatness: BMI had high specificity but only moderate sensitivity for

Table I Characteristics of Study Participants, Mean (SD) or Median (Range)

\begin{tabular}{|l|l|}
\hline Variable & Total \\
\hline Number of participants $(\mathrm{n})$ & 400 \\
Weight $(\mathrm{kg})$ & $68.8(17.2)$ \\
Height $(\mathrm{cm})$ & $158.1(5.1)$ \\
Age $($ decimal years) & $18.3(0.6)$ \\
BMl $\left(\mathrm{kg} / \mathrm{m}^{2}\right)$ & $27.8($ range 15.I-54.0) \\
Fat percentage $(\%)$ & $32.0(5.0-54.0)$ \\
\hline
\end{tabular}

excess fatness in the present study. The finding that BMI was conservative is consistent with previous studies as summarised by systematic reviews, ${ }^{7-9}$ although previous studies have almost all involved participants of white European ethnic origin. Previous systematic reviews found no eligible studies of the accuracy of BMI in Arab children, adolescents, or adults and so the presence of an underestimate and the extent of the underestimate inherent with BMI were unknown prior to the present study. The degree of bias associated with BMI seems to be populationspecific and so there was a need for a study in an Arab population. ${ }^{7-9,12}$ Even lower sensitivity of BMI when compared to body fatness has been reported in some previous studies. In one study of US adult women for example, the BMI-defined obesity prevalence was $35 \%$ while it was $79 \%$ according to a measure of body fatness based on dualenergy X-ray absorptiometry. ${ }^{28}$

The present study suggests that obesity (excessive fatness) is a much more common problem than it appears when BMI is used to define obesity in adolescent females in Kuwait. The present study findings have implications 
Table 2 Summary of Required Items for Reporting of Diagnostic Accuracy Studies, Adapted from ${ }^{27}$

\begin{tabular}{|c|c|}
\hline $\begin{array}{l}\text { Title, } \\
\text { Abstract }\end{array}$ & Identify as diagnostic or classification accuracy study \\
\hline Introduction & Make aim of classification accuracy clear \\
\hline \multirow[t]{10}{*}{ Methods } & Describe design, prospective or retrospective \\
\hline & Describe participant eligibility criteria \\
\hline & $\begin{array}{l}\text { Explain participant's identification and recruitment } \\
\text { sequence }\end{array}$ \\
\hline & Describe the index test and reference method \\
\hline & Provide a rationale for the reference method \\
\hline & Provide a rationale for the test cut-offs chosen \\
\hline & $\begin{array}{l}\text { Test and reference measures known at time of } \\
\text { measurement }\end{array}$ \\
\hline & Describe methods of assessing classification accuracy \\
\hline & $\begin{array}{l}\text { Describe how index and reference measures were } \\
\text { handled }\end{array}$ \\
\hline & Consider sample size \\
\hline \multirow[t]{4}{*}{ Results } & Describe participant flow in a diagram (Figure I) \\
\hline & Provide summary characteristics of participants (Table I) \\
\hline & Describe time between index and reference measures \\
\hline & Provide estimates of classification accuracy ( Table 3) \\
\hline \multirow[t]{2}{*}{ Discussion } & Discuss limitations, uncertainty, generalizability \\
\hline & Discuss policy or practice implications \\
\hline Funding & Provide funding source and conflicts \\
\hline
\end{tabular}

Table 3 Diagnostic Accuracy Summary $(N=400)$

\begin{tabular}{|l|l|l|l|}
\hline $\begin{array}{l}\text { Over Fatness (Defined as Body } \\
\text { Fat percentage } \geq \mathbf{3 0} \text { in Girls) }\end{array}$ & $\begin{array}{l}\text { Yes, } \\
\mathbf{n = 2 4 7}\end{array}$ & $\begin{array}{l}\mathbf{N o}, \\
\mathbf{n = 1 5 3}\end{array}$ & $\begin{array}{l}\text { Total, } \\
\mathbf{n = 4 0 0}\end{array}$ \\
\hline $\begin{array}{l}\text { Obese according to BMI } \\
\text { Non-obese according to BMI }\end{array}$ & 163 & 6 & 169 \\
84 & 147 & 231 \\
\hline
\end{tabular}

for obesity surveillance. Obesity in adolescent girls may be even closer to a crisis point in the GCC states than it appears from national surveys of BMI. ${ }^{1}$ The present study also has implications for studies which use BMI as a proxy for obesity as either an exposure or outcome variable, testing the impact of obesity on health outcomes or the impact of risk factors on obesity as an outcome. The present study found that BMI was a very crude proxy for obesity (excessive fatness) in Kuwaiti adolescent and young adult women, and so where possible it would be more informative to have a direct measure of body fatness rather than a crude proxy such as BMI in future epidemiological studies which aim to understand the causes or consequences of obesity. ${ }^{17}$

The present study had a number of strengths, in particular the novelty of the sample and setting since it seems that no previous studies of the accuracy of BMI to define obesity had been carried out in any Arab sample. ${ }^{7-9}$ There were also some study limitations, including generalisability. The university sample, limited age range, and exclusively female sample recruited, mean that results should be generalised to other samples and settings with caution, although our findings were consistent with previous systematic reviews as noted above. Sensitivity and specificity depend on the prevalence of true positives in the sample, and the present study did not attempt to estimate obesity prevalence in Kuwait, but rather to examine the extent to which obesity prevalence estimates using BMI might be biased, eg in national surveys. An additional limitation was that no "gold standard" measure of body fatness was available. The only gold standard methods of measuring body fatness at present are the multicomponent models ${ }^{29}$ but these are not practical for field studies such as the present study. ${ }^{6}$ However, the field technique of impedance chosen is practical and has acceptable accuracy. ${ }^{21-24} \mathrm{~A}$ final limitation is the fact that the sample size of the present study was fixed at around 400 participants, because the present study was part of a separate study which aimed to test for associations between obesity and academic attainment in university students. The power of the present study is therefore unclear, although it was larger than many previous studies of the diagnostic accuracy of BMI in children and adolescents as reported in previous systematic reviews of the diagnostic accuracy of BMI. ${ }^{7-9}$ In the absence of a gold standard method of measuring body fat, the present study findings did not extend to further analyses such as the area under the curve, and did not attempt to identify the optimal BMI cut-off point for identification of those with excessive fatness. ${ }^{6,26}$

\section{Conclusion}

The standard method of defining obesity based on BMI substantially underestimated the prevalence of obesity (excess fatness) in Kuwaiti adolescent females. Further studies are required to ascertain the extent to which obesity prevalence in Kuwait is being underestimated by the use of BMI in males and in other age groups, but BMI should be considered as a highly conservative proxy for 
body fatness. BMI should also be considered as a crude proxy for body fatness which may be unsuitable for epidemiological studies where obesity is used as either an exposure or an outcome variable.

\section{Acknowledgments}

The authors acknowledge the support of Prof Hummoud Alqashan the Dean of the Social Science college at Kuwait University, and Dr Hamad Alaslwai the Head of Research of the Social Science College, also Ms Shaima Alqattan and, from the Kuwait Institute for Scientific Research, Dr Sameer Alzanki, Dr Tariq, Dr Kazi and Mr Hasan AlAttar, and Dr Manal Eshelli. Thanks also to all of the participants.

\section{Author Contributions}

All authors contributed to data analysis, drafting or revising the article, gave final approval of the version to be published, and agree to be accountable for all aspects of the work.

\section{Funding}

Public Authority for Applied Education and Training, Kuwait. Scottish Funding Council.

\section{Disclosure}

The author reports no conflicts of interest in this work.

\section{References}

1. Al Hammadi H, Reilly J. Prevalence of obesity among school-age children and adolescents in the Gulf cooperation council (GCC) states: a systematic review. BMC Obes. 2019;6(1):3. doi:10.1186/s40608018-0221-5

2. Nahhas MA, Asamoah F, Mullen S, Nwaru BI, Nurmatov U. Epidemiology of overweight and obesity in early childhood in the Gulf Cooperation Council countries: a systematic review and meta-analysis protocol. BMJ Open. 2018;8(6):e019363. doi:10.1136/ bmjopen-2017-019363

3. Musaiger AO, Al-Mannai M, Tayyem R, et al. Prevalence of overweight and obesity among adolescents in seven Arab countries: a cross-cultural study. J Obes. 2012;2012:1-5. doi:10.1155/2012/981390

4. Rey Lopez JP, Hashem R, McMunn A, Whincup P, Owen CG, Stamatakis E. Prevalence of overweight and obesity among Kuwaiti adolescents and associations with socioeconomic indicators. Minerva Pediatr. 2019;71(4):326-332.

5. World Health Organisation. Childhood overweight and obesity. WHO; 2017. Available from: https://www.who.int/dietphysicalactivity/child hood/en/. Accessed September 2, 2019.

6. Diouf A, Adom T, Aouidet A, et al. Body mass index vs deuterium dilution method for establishing childhood obesity prevalence, Ghana, Kenya, Mauritius, Morocco, Namibia, Senegal, Tunisia and United Republic of Tanzania. Bull World Health Organ. 2018;96(11):772-781. doi:10.2471/BLT.17.205948

7. Javed A, Jumean M, Murad MH, et al. Diagnostic performance of body mass index to identify obesity as defined by body adiposity in children and adolescents: a systematic review and meta-analysis. Pediatr Obes. 2015;10(3):234-244. doi:10.1111/ijpo.242
8. Okorodudu DO, Jumean MF, Montori VM, et al. Diagnostic performance of body mass index to identify obesity as defined by body adiposity: a systematic review and meta-analysis. Int J Obes. 2010;34 (5):791-799. doi:10.1038/ijo.2010.5

9. Reilly JJ, Kelly J, Wilson DC. Accuracy of simple clinical and epidemiological definitions of childhood obesity: systematic review and evidence appraisal. Obes Rev. 2010;11:645-65512. doi:10.1111/ j.1467-789X.2009.00709.x

10. Reilly JJ, El-Hamdouchi A, Diouf A, Monyeki A, Somda SA. Determining the worldwide prevalence of obesity. Lancet. 2018;391 (10132):1773-1774. doi:10.1016/S0140-6736(18)30794-3

11. Reilly JJ. Health effects of overweight and obesity in 195 countries. N Engl J Med. 2018;77:1496.

12. Hruschka DJ, Hadley C. How much do universal anthropometric standards bias the global monitoring of obesity and undernutrition? Obes Rev. 2016;17:1030-1039. doi:10.1111/obr.v17.11

13. Booth JN, Tomporowski PD, Boyle JME, et al. Obesity impairs academic attainment in adolescence: findings from ALSPAC, a UK cohort. Int J Obes (Lond). 2014;38(10):1335-1342. doi:10.1038/ ijo.2014.40

14. Martin A, Booth JN, Laird Y, Sproule J, Reilly JJ, Saunders DH. Physical activity, diet and other behavioural interventions for improving cognition and school achievement in children and adolescents with obesity or overweight. Cochrane Database Syst Rev. 2018. doi:10.1002/14651858.CD009728.pub4

15. Basterfield L, Pearce MS, Adamson AJ, et al. Physical activity, sedentary behavior, and adiposity in English children. Am J Prev Med. 2012;42:445-451. doi:10.1016/j.amepre.2012.01.007

16. Janssen X, Basterfield L, Parkinson KN, et al. Non-linear associations between moderate-to-vigorous-intensity physical activity and adiposity across the adiposity distribution during childhood and adolescence: gateshead millennium study. Int J Obes. 2019;43:744-750. doi:10.1038/s41366-018-0188-9

17. Basterfield L, Pearce MS, Adamson AJ, Reilly JK, Parkinson KN, Reilly JJ. Effect of choice of outcome measure on studies of the etiology of obesity in children. Ann Epidemiol. 2012;22:888-891. doi:10.1016/j.annepidem.2012.09.007

18. Androutsos O, Karaniklou A, Gerasimidis K, Reilly JJ, Edwards CAE. Impact of eating and drinking on body composition measurements by bio-electrical impedance. J Hum Nutr Diet. 2016;28:165-171. doi:10.1111/jhn.12259

19. Matthews EL, Hosick PA. Bioelectrical impedance analysis does not detect an increase in total body water following isotonic fluid consumption. Appl Physiol Nutr Metab. 2019;44:1116-1120. doi:10.11 39/apnm-2019-0106

20. Talma H, Chinapaw MJM, Bakker B, HiraSing RA, Terwee CB, Altenburg TM. Bioelectrical impedance analysis to estimate body composition in children and adolescents: a systematic review and evidence appraisal of validity, responsiveness, reliability and measurement error. Obes Rev. 2013;14(11):895-905. doi:10.1111/obr.12061

21. Burns RD, Fu Y, Constantino N. Measurement agreement in percent body fat estimates among laboratory and field assessments in college students. PLoS One. 2019;14(3):e0214029. doi:10.1371/journal. pone.0214029

22. Barreira TV, Staiano AE, Katzmarzyk PT. Validity assessment of a portable bioimpedance scale to estimate body fat percentage in white and African-American children and adolescents. Pediatr Obes. 2013;8(2):e29-e32. doi:10.1111/j.2047-6310.2012.00122.x

23. Butcher A, Kabiri LS, Brewer W, Ortiz A. Criterion validity and sensitivity to change of a pediatric bioelectrical impedance analysis scale in adolescents. Child Obes. 2019;15(2):142-148. doi:10.1089/ chi. 2018.0183

24. Williams J, Wake M, Campbell M. Comparing estimates of body fat in children using published bioelectrical impedance analysis equations. Int J Pediatr Obes. 2007;2(3):174-179. doi:10.1080/ 17477160701408783 
25. Williams DP, Going SB, Lohman TG, et al. Body fatness and risk for elevated blood pressure, total cholesterol, and serum lipoprotein ratios in children and adolescents. Am J Public Health. 1992;82 (3):358-363. doi:10.2105/AJPH.82.3.358

26. Akobeng AK. Understanding diagnostic tests 1: sensitivity, specificity and predictive values. Acta Paediatr. 2007;96(3):338-341. doi:10.1111/j.1651-2227.2006.00180.x

27. Bossuyt PM, Reitsma JB, Bruns DE, et al.; For the STARD Group. STARD 2015: an updated list of essential items for reporting diagnostic accuracy studies. BMJ. 2015;351:h5527. doi:10.1136/bmj.h5527
28. Shah NR, Braverman ER. Measuring adiposity in patients: the utility of body mass index (BMI), percent body fat, and leptin. Nizami Q, ed. PLoS One. 2012;7(4):e33308. doi:10.1371/journal. pone. 0033308

29. Wells JCK, Fewtrell MS. Measuring body composition. Arch Dis Child. 2006;91(7):612-617. doi:10.1136/adc.2005.085522

Diabetes, Metabolic Syndrome and Obesity: Targets and Therapy

\section{Publish your work in this journal}

Diabetes, Metabolic Syndrome and Obesity: Targets and Therapy is an international, peer-reviewed open-access journal committed to the rapid publication of the latest laboratory and clinical findings in the fields of diabetes, metabolic syndrome and obesity research. Original research, review, case reports, hypothesis formation, expert opinion and commentaries are all considered for publication. The manuscript management system is completely online and includes a very quick and fair peer-review system, which is all easy to use. Visit http://www.dovepress.com/testimonials.php to read real quotes from published authors. 